\title{
Uterine artery Doppler study for the prediction and the severity of the hypertensive disorders during pregnancy
}

\author{
Saptarshi Chakraborty*, Surabhi Saharan
}

Department of Obstetrics and Gynecology, Mahatma Gandhi Medical College and Hospital, Sitapura, Jaipur, Rajasthan, India

Received: 07 June 2017

Accepted: 12 June 2017

*Correspondence:

Dr. Saptarshi Chakraborty,

E-mail: saptarshichakraborty8@gmail.com

Copyright: (c) the author(s), publisher and licensee Medip Academy. This is an open-access article distributed under the terms of the Creative Commons Attribution Non-Commercial License, which permits unrestricted non-commercial use, distribution, and reproduction in any medium, provided the original work is properly cited.

\begin{abstract}
Background: Hypertensive disorder in pregnancy is one of the major cause of maternal and perinatal mortality and morbidity worldwide particularly in developing countries. In developed countries, maternal mortality rate varies from 4-40 per 1 lakh live birth. In developing countries, it varies from 100-700 with India having 178 per 1 lakh live birth. Objectives were to study of uterine artery Doppler for the prediction of hypertensive disorders and its severity, Sensitivity and Specificity of Uterine Artery Doppler and their comparison for the prediction and the severity of hypertensive disorders during pregnancy.

Methods: This is a prospective study. Approximately hundred patients with hypertensive disorders during pregnancy attending the OPD and IPD in Obstetrics and Gynecology Department will be included. All the patients in this study group will be subjected to Ultrasonographic evaluation of the pregnancy along with the Arterial Doppler of both the Uterine Artery and Umbilical Artery will be done.

Results: Using uterine artery Doppler Study in combination is significantly useful in early prediction of PIH having specificity and sensitivity of Uterine artery Doppler study - Pi Index as $91.67 \%$ and $85.71 \%$, Ri Index as $87.5 \%$ and $71.43 \%$ and diastolic notch as $94.44 \%$ and $92.85 \%$ respectively. The use of uterine artery Doppler Study as an important tool for early prediction of PIH and has a lot of prognostic value.

Conclusions: The predictive accuracy of uterine artery Doppler study using Pi Index and Ri Index is better in the detection of early-onset PIH, than the late-onset disease. Thereby, it will help in the long run to prevent the increasing maternal and fetal morbidity and mortality.
\end{abstract}

Keywords: Hypertensive disorders, Pregnancy, Uterine artery doppler

\section{INTRODUCTION}

Hypertensive disorders of pregnancy are one of the major cause of maternal and perinatal mortality and morbidity worldwide particularly in developing countries. Hypertensive disorder of pregnancy is a sign of an underlying pathology which may be pre existing or appear for the first time during pregnancy. The identification of this clinical problem and effective management plays a significant role in the prevention of the adverse effects on pregnancy outcome. ${ }^{1}$ Hypertensive Disorders of Pregnancy is a multi-system disorder, which is characterized by new onset hypertension (systolic and diastolic blood pressure of $\geq 140$ and $90 \mathrm{~mm} \mathrm{Hg}$, respectively, on two occasions, at least 6 hours apart) and proteinuria (protein excretion of $\geq 300 \mathrm{mg}$ in a $24 \mathrm{~h}$ urine collection, or a dipstick of $\geq 2+$ ), that develop after 20 weeks of gestation in previously Normotensive women. ${ }^{2}$ 
Hypertensive Disorders of Pregnancy can have an early onset (preeclampsia starting before 34 weeks of gestation) or late onset (preeclampsia starting after 34 weeks of gestation), can show mild or severe symptoms (systolic blood pressure $\geq 160 \mathrm{mmHg}$ or diastolic blood pressure $\geq 110 \mathrm{mmHg}$, proteinuria $>5 \mathrm{~g} / 24$ hours, oliguria, neurological symptoms, other clinical symptoms such as deranged liver function, thrombocytopenia $<100$ $000 \mathrm{~mm} 3$, HELLP syndrome), and can evolve in eclampsia in the most severe cases whereas Eclampsia is the occurrence of one or more convulsions superimposed on the syndrome of pre-eclampsia. ${ }^{3}$

Dependent on the systemic involvement along with several other symptoms, such as edema, disturbance of hemostasis, renal or liver failure, and the HELLP syndrome (hemolysis, elevated liver enzymes, and low platelet counts) also complicates the clinical picture.

Most theories on the etiology of hypertensive disorders of pregnancy suggests that the disease is a cascade triggered by combination of abnormal maternal inflammatory response, endothelial cell activation/damage with deranged hemodynamic milieu, and deranged immunity. ${ }^{4,5}$

Numerous patho-physiological mechanisms, alone or in combination, have been suggested to be responsible for the diverse subsets of hypertensive disorders of pregnancy.

They include impaired vascular remodeling of the maternal-fetal interface, excessive immune response to paternal antigens, systemic inflammatory response, and dysfunctional placental or endothelial response, all of these processes being modulated by genetic and environmental parameters. Such heterogenicity of potential processes leading to, or resulting from, hypertensive disorders of pregnancy has contributed to the lack of diagnostic means for identification of women susceptible to developing pre-eclampsia, resulting in delayed recognition and severe complications and impeding evaluation of new preventive interventions. ${ }^{6}$

Since there is an involvement of various organ systems, the potential markers would include inhibin A, PAPP-A, Activin A, angiotensin 11 sensitivity, urine albumin excretion, uric acid and microproteinuria, urinary inhibina, urinary kallikrein -calcium/kallikrein ratio, maternal serum alpha fetoprotein; coagulation and platelet activation. $^{7}$

Risk factors for preeclampsia include nulliparity, multifetal gestations, previous history of preeclampsia, obesity, diabetes mellitus, vascular and connective tissue disorders like systemic lupus erythematosus and antiphospholipid antibodies, age $>35$ years at first pregnancy, smoking, and African American race.
Ultrasonography Color Doppler study may also help in the prediction of hypertensive disorder. Persistence of high impedance to blood flow in the uterine arteries of women with hypertension, which is one of the indirect evidence of abnormal placentation also helps in early identification of disease. ${ }^{8}$ The changes are increased systolic to diastolic ratio, absent diastolic flow, reverse diastolic flow depending upon severity of the disease. ${ }^{9}$ With the help of Uterine Artery Doppler Velocity waveform analysis we can measure resistance index, pulsatility index, systolic/diastolic ratio, diastolic/systolic ratio, presence of any diastolic notch. ${ }^{10}$

The specificity and sensitivity of the Uterine Artery Color Doppler Study for Pi Index are $91.67 \%$ and $85.71 \%$, Ri Index $87.5 \%$ and $71.43 \%$ and for Diastolic Notch are $94.44 \%$ and $92.86 \%$ which is very useful in early detection of PIH. ${ }^{11}$ Therefore, Ultrasonography Color Doppler study may also help in the prediction of hypertensive disorder. Persistence of high impedance to blood flow in the uterine arteries of women with hypertension, which is one of the indirect evidence of abnormal placentation also helps in early identification of disease. ${ }^{12}$ The changes are increased systolic to diastolic ratio, absent diastolic flow, reverse diastolic flow depending upon severity of the disease. ${ }^{13,14}$

WHO, UNFPA, UNICEF, IPPFF, the population council and other national \& international agencies concerned with safe motherhood concluded that it is possible to reduce maternal mortality significantly with investigation and its effective management. ${ }^{15}$

Reducing maternal mortality by $75 \%$ between 1990 and 2015 has been considered as part of the millennium development goals of the World Health Organization (WHO) Nations. ${ }^{15}$

The present study was undertaken to study of biochemical markers and uterine artery Doppler for the prediction of hypertensive disorders and its severity; sensitivity and specificity of biochemical markers and uterine artery Doppler and their comparison for the prediction and the severity of hypertensive disorders during pregnancy and to know the maternal and perinatal outcome in these patients.

\section{METHODS}

This is a prospective study done at Mahatma Gandhi Medical College and Hospital, Sitapura, Jaipur. Approximately 100 patients, during pregnancy attending the OPD and IPD in Obstetrics and Gynecology Department will be included. Patient's detailed clinical history, personal history, significant medical history, obstetric history and menstrual history will be taken.

General examination of all the patients will be done and Pulse, Blood Pressure, Temperature and Respiratory Rate 
will be noted. Systemic examination including heart, lungs and other systems will be examined in detail.

All the patients in this study group will be subjected to all the routine blood tests and special tests, including biochemical markers. A detailed Ultrasonographic evaluation of the pregnancy along with the Arterial Doppler of both the Uterine Artery and Umbilical Artery will be done. All patients will be kept in the regular follow up and in the end, their maternal and fetal outcome will also be noted.

Special blood tests will be including:

- Complete blood count (specially hemoglobin and platelet count),

- Liver function tests including SGOT, SGPT, Alkaline Phosphatase Level, LDL Level and PT/INR.

- Lipid profile - LDL, HDL, Triglyceride, Total Cholesterol, VLDL.

- Biochemical Markers- Serum Uric Acid, Blood Urea, Serum Creatinine, Activin-A, Pregnancy Associated Plasma Protein-A (PAPP-A)

- Urinary Tests- Urinary Micro Albumin Level, Urine Protein/Creatinine Ratio, Urinary Calcium Creatinine Ratio.

In the Doppler study following parameters will be assessed:

- Pulsatility Index - a measure of the variability of the blood velocity in a vessel, equal to the difference between the peak systolic and minimum diastolic velocities divided by the mean velocity during the cardiac cycle.

Calculated by $=$ Peak systolic velocity - end diastolic velocity/mean velocity

- Resistance Index - is a measure of pulsatile blood flow that reflects the resistance to blood flow caused by microvascular bed distal to the site of measurement.

- $\quad$ Calculated by = Peak systolic velocity - end diastolic velocity/peak systolic velocity

- Systolic to Diastolic Ratio - determinations of blood flow velocities that reflects intrinsic resistance in an arterial blood vessel.

- Presence and absence of the diastolic in both the uterine arteries.

\section{Statistical analysis}

Using Statistical test i.e. Z-test where the distribution of the test statistic under the null hypothesis can be approximated by a normal distribution, using expected value $\theta$ of $\mathrm{T}$ under the null hypothesis, and then obtaining an estimate $S$ of the standard deviation of $T$, the standard score $Z=(T-\theta) / s$ is calculated, will be applied wherever needed.
With the help of these statistical methods, the sensitivity and the specificity of the biological markers and the Uterine Artery Doppler study will be calculated.

\section{RESULTS}

Using Uterine Artery Doppler Study is significantly useful in early prediction of PIH having specificity and sensitivity of Uterine artery Doppler study - Pi Index as $91.67 \%$ and $85.71 \%$, Ri Index as $87.5 \%$ and $71.43 \%$ and diastolic notch as $94.44 \%$ and $92.85 \%$ respectively.

Hence, the Uterine Artery Doppler study should be an integral component for the early diagnosis of PIH patients, and has an important role in the management of pregnant patients and to prevent maternal and foetal complications.

Table 1: Distribution of the cases according to age.

\begin{tabular}{|lll|}
\hline Age in years & No. of pts & $\%$ \\
\hline $20-24$ & 48 & 48 \\
\hline $25-29$ & 27 & 27 \\
\hline $29-33$ & 17 & 17 \\
\hline $34-38$ & 7 & 7 \\
\hline $39-40$ & 1 & 1 \\
\hline Total & 100 & 100 \\
\hline
\end{tabular}

Table 1 showed the age distribution of 100 patients of my study group that maximum patients $38 \%$ were in the age of 20-24 years and second most common were in the age group in between $25-29$ years that was $27 \%$. While only 8 patients were above 35 years.

Table 2: Distribution of the cases according to parity.

\begin{tabular}{|lll|}
\hline Parity & No. of pts & $\%$ \\
\hline Para 1 & 22 & 81 \\
\hline Para 2 & 32 & 12 \\
\hline Para 3 & 20 & 3 \\
\hline Para 4 & 18 & 2 \\
\hline Para 5 & 7 & 2 \\
\hline Total & 100 & \\
\hline
\end{tabular}

In present study of 100 patients, maximum number of patients was primigravida $(81 \%)$, while multiparous women were $19 \%$.

Table 3: Distribution of the cases according to occupation.

\begin{tabular}{|lll|}
\hline Wife occupation & Number & $\%$ \\
\hline Farmer & 6 & 6 \\
\hline Housewife & 84 & 84 \\
\hline Labour & 1 & 1 \\
\hline Nurse & 3 & 3 \\
\hline Self Employed & 1 & 1 \\
\hline Sweeper & 1 & 1 \\
\hline Teacher & 4 & 4 \\
\hline
\end{tabular}


In this study of 100 patients, maximum number of patients $84 \%$ was from house wife while 16 had their own jobs (4 were teacher, 3 had nursing job, 6 were working in the field etc.)

Table 4: Distribution of the cases according to residence.

\begin{tabular}{|lll|}
\hline Location & Number & $\%$ \\
\hline Rural & 56 & 56 \\
\hline Urban & 44 & 44 \\
\hline Total & 100 & 100 \\
\hline
\end{tabular}

In present study of 100 patients, 56 patients were residing in rural area while $44 \%$ in urban area.

Table 5: Distribution of the cases according to socioeconomic status (Kuppuswami Scale).

\begin{tabular}{|lll|}
\hline SE. Status & Number & $\%$ \\
\hline Lower Class & 65 & 65 \\
\hline Middle Class & 31 & 31 \\
\hline Upper Class & 4 & 4 \\
\hline Total & 100 & 100 \\
\hline
\end{tabular}

In current study, of 100 patients, 65 patients were from lower socioeconomic group, while only 4 patients belong to upper class and 34 were from middle class.
Table 6: Distribution of cases according to gestational weeks.

\begin{tabular}{|lll|}
\hline Gestational period & No. of pts & $\%$ \\
\hline $16-20$ weeks & 24 & 24 \\
\hline $20-24$ weeks & 36 & 36 \\
\hline $25-29$ weeks & 65 & 65 \\
\hline Total & 125 & 125 \\
\hline
\end{tabular}

In present study, 125 normotensive patients were taken in different gestational period. 24 patients were registered between 16-20 weeks, out of which 9 patients were registered and 15 patients were dropped off, while 36 were between 20-24 weeks out of which 26 patients were registered and 10 patients were dropped off and 65 patients were in the gestation period of 25-29 weeks and came for proper follow up and further investigations.

Table 7: Distribution of cases according to gestational weeks.

\begin{tabular}{|lll|}
\hline Gestational period & No. of pts & $\%$ \\
\hline $16-20$ weeks & 9 & 9 \\
\hline $20-24$ weeks & 26 & 26 \\
\hline $25-29$ weeks & 65 & 65 \\
\hline Total & 100 & 100 \\
\hline
\end{tabular}

Table 8: Doppler study of uterine artery (Pi Index for predicting PIH at different gestational period).

\begin{tabular}{|c|c|c|c|c|c|c|}
\hline Pi Index & $\mathrm{PIH}=28$ & \multirow{3}{*}{$\begin{array}{l}\text { Normal } \\
\text { (TN) }\end{array}$} & \multirow{3}{*}{$\begin{array}{l}\text { Elevated Level } \\
\text { (FP) }\end{array}$} & \multirow{3}{*}{$\begin{array}{l}\text { Normal } \\
\text { (FN) }\end{array}$} & \multirow[b]{2}{*}{$\begin{array}{l}\text { Elevated } \\
(\mathrm{TP})\end{array}$} & \multirow[b]{3}{*}{ Severe PIH } \\
\hline \multirow[t]{2}{*}{ Gestational period } & \multirow{2}{*}{$\begin{array}{l}\text { Total No. Of } \\
\text { Patients }\end{array}$} & & & & & \\
\hline & & & & & Mild PIH & \\
\hline $16-20$ weeks & 9 & 6 & 1 & 1 & 1 & 0 \\
\hline 20-24 weeks & 26 & 19 & 2 & 1 & 3 & 1 \\
\hline 25-29 weeks & 65 & 41 & 3 & 2 & 15 & 4 \\
\hline Total & 100 & 66 & 6 & 4 & 19 & 5 \\
\hline
\end{tabular}

Table 9: Doppler study of uterine artery (Ri Index for predicting PIH at different gestational period).

\begin{tabular}{|lllllll|}
\hline Ri Index & PIH=28 & & & & \\
\hline Gestational period & Total no. of patients & Normal (TN) & Elevated (FP) & Normal (FN) & Elevated (TP) \\
\hline 16-20 weeks & 9 & 5 & 2 & 1 & 1 & 0 \\
\hline 20-24 weeks & 26 & 14 & 4 & 4 & 2 \\
\hline 25-29 weeks & 65 & 44 & 3 & 3 & 6 & 9 \\
\hline Total & 100 & 63 & 9 & 8 & 9 & 11
\end{tabular}

In this study group 100 normotensive patients in different gestational period.9\% patients were registered between 16-20 weeks, while $26 \%$ were between the $20-24$ weeks and 65 patients were in the gestation period of 25-29 weeks, were counseled and accepted for follow-up and further investigations in their gestational period. Table 8 showed Pi Index of 100 patients at different gestational period. On follow-up out of 100 patients at different gestational periods (16-20 weeks - 9 patients, 21-24 weeks - 26 patients, 25-29 weeks - 65 patients), there were 72 normotensive patients, 66 patients had normal Pi Index while 6 patients had slightly elevated level. Out of $28 \mathrm{PIH}$ patients 24 patients had elevated Pi Index and 4 had normal Pi Index. This result showed the specificity 
and sensitivity of Pi Index as $91.67 \%$ and $85.71 \%$ and having a PPV of $80 \%$, NPV of $94.29 \%$ and accuracy of $90 \%$. In this Table $9 \mathrm{Ri}$ Index depicting of 100 patients in this table at different gestational weeks (16-20 weeks-9 patients, 21-24 weeks -26 patients, 25-29 weeks-65 patients). On follow up out of 100 normotensive patients, 72 patients remained normotensive and in these 63 patients had normal Ri Index, while 9 had slight elevated level. 28 patients developed PIH on follow-up, out of which 20 patients showed elevated level of Ri Index, while 8 patients had normal Ri Index. Hence the specificity and sensitivity of $\mathrm{Ri}$ Index are respectively $87.5 \%$ and $71.43 \%$, which is followed by $68.87 \%$ of PPV, $88.73 \%$ of NPV and accuracy of $83 \%$.

Table 10: Doppler study of uterine artery (diastolic notch predicting PIH at different gestational period).

\begin{tabular}{|c|c|c|c|c|c|}
\hline Diastolic notch & $\mathrm{PIH}=28$ & & & & \\
\hline Gestational period & No. of pts & Present (FN) & Absent (TN) & Present (TP) & Absent (FP) \\
\hline $16-20$ weeks & 9 & 4 & 3 & 1 & 1 \\
\hline 20-24 weeks & 26 & 9 & 5 & 10 & 2 \\
\hline 25-29 weeks & 65 & 44 & 7 & 10 & 4 \\
\hline Total & 100 & 57 & 15 & 21 & 7 \\
\hline
\end{tabular}

Table 10 showed Doppler Study of Uterine Artery for Diastolic Notch of 100 patients at different gestational weeks (16-20 weeks - 9 patients, 21-24 weeks - 26 patients, 25-29 weeks - 65 patients). On follow-up out of 100 patients, 57 patients had absent diastolic notch, while 15 patients had diastolic notch present under the 72 normotensive patients. Out of 28 patients who developed PIH on follow-up, 21 patients had diastolic notch present, while 7 patients had absent diastolic notch. This table showed the specificity and sensitivity of $94.44 \%$ and 92.85\% respectively while PPV was $94.44 \%$, NPV $86.67 \%$ and accuracy of $94 \%$.

Table 11: Specificity and sensitivity table for uterine artery Doppler study for prediction of PIH.

\begin{tabular}{|c|c|c|c|c|c|c|}
\hline \multicolumn{7}{|c|}{ Total no. of patients $=100$} \\
\hline \multicolumn{3}{|c|}{ Normotensive $=72$ Patients } & \multicolumn{2}{|c|}{ PIH=28 Patients } & \multirow[t]{2}{*}{ Specificity } & \multirow[t]{2}{*}{ Sensitivity } \\
\hline & $\begin{array}{l}\text { Normal } \\
\text { level (TN) }\end{array}$ & $\begin{array}{l}\text { PIH (Elevated } \\
\text { level) }(\text { FP) }\end{array}$ & Normal level (FN) & Elevated (TP) & & \\
\hline Pi Index & 66 & 6 & 4 & 24 & $91.67 \%$ & $85.71 \%$ \\
\hline Ri Index & 63 & 9 & 8 & 20 & $87.5 \%$ & $71.43 \%$ \\
\hline Diastolic notch & 68 & 4 & 2 & 26 & $94.44 \%$ & $92.86 \%$ \\
\hline
\end{tabular}

Table 11 showed Doppler Study of Uterine Artery depicting 100 patients. In this study, Pi Index, Ri Index and Diastolic Notch in the 100 patients was done, it was observed that Pi Index were normal in 66 patients and elevated in 6 patients whereas in Ri Index 63 patients were normal and 6 elevated and in diastolic notch 68 patients were having absent notch and 4 patients had notch present out of 72 patients who were normotensive on follow-up. Whereas in case of PIH, in Pi Index 24 patients were having elevated index and 4 patients were in normal value, in $\mathrm{Ri}$ Index 20 patients were having elevated $\mathrm{Ri}$ Index and 8 patients were having normal value and in diastolic notch 26 patients had present notch and 2 had absent out of 28 patients. In this study, I observed that the specificity and sensitivity of Pi Index, Ri Index and Diastolic Notch were $91.67 \%, 87.5 \%$ and $94.44 \%$ and $85.71 \%, 71.43 \%$ and $92.86 \%$ respectively along with Pi Index PPV 80\%, NPV 94.29\% and accuracy of $90 \%$, whereas Ri Index PPV $68.97 \%$, NPV $88.73 \%$ and accuracy of $83 \%$ and diastolic notch PPV 86.67\%, NPV 97.14\% and accuracy 94\% showing Pi Index is having higher specificity and sensitivity along with other parameters after diastolic notch.

\section{DISCUSSION}

Pregnancy induced hypertension is the most common obstetrical disorder world-wide and on a national scale in India also. It is one of the major causes of maternal and fetal mortality.

\section{Distribution according to age group}

In present study, 55\% were present between 20- 35 years, $7 \%$ 34-38yrs and 1\% 39-40yrs. Same age groups were studied by Sajith $\mathrm{M}$ et al in their study had 1330 patients, 
out of which 104 were between the age group of 18-32 years. ${ }^{16}$

\section{Distribution according to parity}

In my study on the basis of parity showed that maximum number of patients were from the Primigravidae group comprising about $81 \%$ of the total patients.

Kooffreh ME et al in their study on the prevalence of preeclampsia among pregnant women including 8524, showed that majority of the patients between the age group of 25-29 years that is about 104 patients were Primigravida. ${ }^{17}$

\section{Distribution according to occupation}

In present study, out of 100 patients $84 \%$ were housewives and $16 \%$ were working women.

Singh $S$ in their study on Hypertensive disorders in pregnancy among pregnant women showed that maximum number of patients that is $88.13 \%$ were housewives. $^{18}$

\section{Distribution according to residence}

In this study, maximum numbers of patients were from rural area i.e. $56 \%$.

Saxena $S$ et al in their study on Socio-demographic Profile of Pregnancy Induced Hypertension in a Tertiary Care Centre showed that maximum number of patients that is $77.14 \%$ were residing in rural area. ${ }^{19}$

\section{Distribution of the cases according to socioeconomic status}

In present study, maximum number of patients i.e. $65 \%$ were from lower socioeconomic status. Aabidha PM et al in their study on Maternal and fetal outcome in preeclampsia in a secondary care hospital in South India showed that maximum number of patients $61 \%$ were from lower socioeconomic status. ${ }^{20}$

\section{Uterine artery Doppler study specificity and sensitivity in the prediction of PIH}

It showed that Doppler Study of Uterine Artery depicting 100 patients. In this table out of 100 patients, Pi Index was normal in 66 patients and elevated in 6 patients, out of 72 normotensive patients, whereas in $\mathrm{Ri}$ Index 63 patients were normal and 6 elevated, out of 72 normotensive patients and in diastolic notch 68 patients were having absent notch and 4 patients had notch present out of 72 patients who were normotensive on follow-up. Whereas in case of $28 \mathrm{PIH}$ patients, Pi Index was elevated in 24 patients and 4 patients were in normal value, whereas in $\mathrm{Ri}$ Index 20 patients were having elevated $\mathrm{Ri}$ Index and 8 patients were having normal value and in diastolic notch 26 patients had present notch and 2 had absent. This table showed the specificity and sensitivity of Pi Index, Ri Index and diastolic Notch as $91.67 \%, 87.5 \%$ and $94.44 \%$ and $85.71 \%, 71.43 \%$ and $92.86 \%$ respectively along with Pi Index PPV 80\%, NPV $94.29 \%$ and accuracy of $90 \%$, whereas $\mathrm{Ri}$ Index PPV $68.97 \%$, NPV $88.73 \%$ and accuracy of $83 \%$ and diastolic notch PPV $86.67 \%$, NPV $97.14 \%$ and accuracy $94 \%$ showing $\mathrm{Pi}$ Index is having higher specificity and sensitivity along with other parameters after diastolic notch.

Funding: No funding sources

Conflict of interest: None declared

Ethical approval: The study was approved by the Institutional Ethics Committee

\section{REFERENCES}

1. Vidya GS, Lalitha K, Hemanth T, Murthy NS. Prevalence of adverse pregnancy outcomes: a community based longitudinal study. JEMDS. 2015;4(50):8720-6.

2. Fisher SJ. The placental problem: linking abnormal cytotrophoblast differentiation to the maternal symptoms of preeclampsia. Reprod Biol Endocrinol. 2004;2(1):53.

3. Steegers EA, von Dadelszen P, Duvekot JJ, Pijnenborg R. Pre-eclampsia. Lancet. 2010;376(9741):631-44.

4. Aloizos S, Seretis C, Liakos N, Aravosita P, Mystakelli C, Kanna E et al. HELLP syndrome: understanding and management of a pregnancyspecific disease. J Obstet Gynecol. 2013;33(4):331-7.

5. Mele C, Remuzzi G, Noris M. Hemolytic uremic syndrome. InSeminars in Immunopathology. 2014;36(4):399-420.

6. Thaler I, Manor D, Itskovitz J, Rottem S, Levit N, Timor-Tritsch I et al. Changes in uterine blood flow during human pregnancy. Am J Obstet Gynecol. 1990;162(1):121-5.

7. Conde-Agudelo AG, Romero RO, Lindheimer MD. Tests to predict preeclampsia. Chesley's hypertensive disorders in pregnancy. Amsterdam: Academic Press, Elsevier. 2009:189-211.

8. Jeyabalan A. Epidemiology of preeclampsia: impact of obesity. Nutr Rev. 2013;71(suppl 1):S18- 25.

9. Trudinger BJ, Giles WB, Cook CM, Bombardieri J, Collins LE. Fetal umbilical artery flow velocity waveforms and placental resistance: clinical significance. BJOG: Int $\mathbf{J}$ Obstet Gynecol. 1985;92(1):23-30.

10. Fay RA, Ellwood DA, Bruce S, Turner A. Color Doppler imaging of the uteroplacental circulation in the middle trimester: observations on the development of a low-resistance circulation. Ultrasound Obstet Gynecol. 1994;4(5):391-5.

11. Harrington KD, Cooper D, Lees C, Hecher K, Campbell S. Doppler ultralsound of the uterine arteries: the importance of bilateral notching in the 
prediction of pre-eclampsia, placental abruption or delivery of a small-for-gestational-age baby. Ultrasound Obstet Gynecol. 1996;7(3):182-8.

12. Bhatt CJ, Arora J, Shah MS. Role of color Doppler in pregnancy induced hypertension (A study of 100 cases). Indian J Radiol Imaging. 2003;13(4):417.

13. Cnossen JS, Morris RK, Riet G, Mol BW, van der Post JA, Coomarasamy A et al. Use of uterine artery Doppler ultrasonography to predict pre-eclampsia and intrauterine growth restriction: a systematic review and bivariable meta-analysis. Canadian Med Assoc J. 2008;178(6):701-11.

14. Oloyede OA, Iketubosin F. Uterine artery Doppler study in second trimester of pregnancy. Pan Afr Med J. 2013;15(1):87.

15. AbouZahr C. Cautious champions: international agency efforts to get safe motherhood onto the agenda. Safe motherhood strategies: A review of the evidence. 2001. Available at http://www.jsieurope.org/safem/collect/safem/pdf/s2 946e/s2946e.pdf.

16. Sajith M, Nimbargi V, Modi A, Sumariya R, Pawar A. Incidence of pregnancy induced hypertension and prescription pattern of antihypertensive drugs in pregnancy. Age (years). 2014;23:4-0.

17. Kooffreh ME, Ekott M, Ekpoudom DO. The prevalence of pre-eclampsia among pregnant women in the University of Calabar Teaching Hospital, Calabar Prevalence. 2014;3(3):133-6.

18. Singh S, Ahmed EB, Egondu SC, Ikechukwu NE. Hypertensive disorders in pregnancy among pregnant women in a Nigerian Teaching Hospital. Nigerian Med J. 2014;55(5):384.

19. Saxena S, Srivastava PC, Thimmaraju KV, Mallick AK, Dalmia K, Das B. Socio-demographic profile of pregnancy induced hypertension in a tertiary care centre. Sch J App Med Sci. 2014;2(6D):3081-6.

20. Aabidha PM, Cherian AG, Paul E, Helan J. Maternal and fetal outcome in pre-eclampsia in a secondary care hospital in South India. J Fam Med Prim Care.

Cite this article as: Chakraborty $\mathrm{S}$, Saharan $\mathrm{S}$. Uterine artery Doppler study for the prediction and the severity of the hypertensive disorders during pregnancy. Int J Reprod Contracept Obstet Gynecol 2017;6:2900-9. 